\title{
NOTE
}

\section{Synthesis of PAMAM Dendrimers Possessing [2.2]Paracyclophane on Their Surface}

\author{
By Yasuhiro MoriSAKI, ${ }^{*}$ Yoshiyuki SHIOTANI, Lin LIN, and Yoshiki CHUJO*
}

\section{KEY WORDS: PAMAM Dendrimer / [2.2]Paracyclophane / $\pi-\pi$ Interaction / CT Complex / Photoluminescence /}

Cyclophane compounds, particularly those comprising intramolecular face-to-face-oriented $\pi$-conjugated systems, have been well-acknowledged in the field of organic chemistry. ${ }^{1}$ Among them, benzene rings of [2.2]paracyclophane are rigidly held with two ethylenes at para positions, and a distance between two benzene rings is $2.8-3.1 \AA$. This class of cyclophanes has been central to the cyclophane chemistry since the first synthesis of [2.2] paracyclophane. ${ }^{2}$ A number of cyclophane compounds have been synthesized till date, and their unique structural, optical, and electronic properties have been investigated in detail. ${ }^{1-3}$ However, there were a few studies on cyclophane-containing polymers $^{4-9}$ in spite of the remarkable progress in cyclophane chemistry except for our reports on conjugated polymers containing cyclophane units in the main chain; ${ }^{9,10}$ additionally, there have been no studies on the synthesis of cyclophane-containing dendrimers.

On the other hand, dendrimers ${ }^{11}$ are well-defined macromolecules that are distinct from the corresponding linear polymers due to their unique spherical and symmetric architecture. ${ }^{12}$ Functionalization of the dendrimer core, branch, and surface are readily carried out, and properties of the resulting dendrimers have been extensively studied. Cyclophanes have optically, electrically, and topologically various intriguing features, which arise from characteristic transannular $\pi-\pi$ interactions between two co-facial $\pi$-electron systems. Thus, we decided to install cyclophane compounds into the dendrimer framework.

Herein we report synthesis and properties of [2.2]paracyclophane-containing dendrimers based on the polyamidoamine dendrimer (PAMAM dendrimer). In this work, we succeeded in the first synthesis of third- and fourth-generation PAMAM dendrimers possessing [2.2]paracyclophane on their surface.

\section{EXPERIMENTAL}

\section{General}

${ }^{1} \mathrm{H}$ and ${ }^{13} \mathrm{C}$ NMR spectra were recorded on a JEOL EX400 instrument at 400 and $100 \mathrm{MHz}$, respectively. Samples were analyzed in $\mathrm{CDCl}_{3}$ or $\mathrm{CD}_{3} \mathrm{OD}$, and the chemical shift values were expressed relative to $\mathrm{Me}_{4} \mathrm{Si}$ as an internal standard. FT-IR spectra were obtained on a Perkin-Elmer 1600 spectrometer in
$\mathrm{KBr}$ pellets. UV-vis spectra were obtained on a JASCO V-530 spectrophotometer or a SHIMADZU UV-3600 spectrophotometer at room temperature. Photoluminescence and excitation spectra were recorded on a Perkin-Elmer LS50B luminescence spectrometer at room temperature. Gel permeation chromatography (GPC) was carried out on TOSOH UV-8020 and RI 8020 equipped with TSKgel $\alpha-3000$ column using DMF (containing $10 \mathrm{mM}$ of $\mathrm{LiBr}$ ) as an eluent after calibration with standard polystyrene samples. Analytical thin-layer chromatography (TLC) was performed with silica gel 60 Merck F254 plates. Gel filtration chromatography was performed with Sephadex LH-20. Column chromatography was performed with Wakogel C-300 silica gel. MALDI-TOF-MS analysis was performed on an Axima-CFR instrument from Shimadzu Bioteck Kratos Analytical. The device is a high resolution, floor-standing instrument equipped with a pulsed $\mathrm{N}_{2}$ laser (wavelength $337 \mathrm{~nm}$, pulse width $4 \mathrm{~ns}$ ); a mixture of 2,5-dihydroxybenzoic acid (DHB) and $\mathrm{D}-(+)$-fucose $(\mathrm{v} / \mathrm{v}=1: 1)$ was used as a matrix. ${ }^{13}$ High-resolution mass spectra (HRMS) were obtained on a JEOL JMS-SX102A spectrometer.

\section{Materials}

All solvents and chemicals were of reagent grade quality, obtained commercially, and used without further purification except as noted below. $\mathrm{Et}_{2} \mathrm{O}$ and THF were distilled from sodium benzophenoneketyl. Triethylamine $\left(\mathrm{NEt}_{3}\right)$, toluene, and dichloromethane were distilled from $\mathrm{KOH}, \mathrm{CaH}_{2}$, and $\mathrm{CaCl}_{2}$, respectively. Propylamine was distilled from zinc dust. Ethylenediamine core amine-terminated PAMAM dendrimer $\mathrm{G}=$ 3.0 (CAS number 153891-46-4) and $\mathrm{G}=4.0$ (CAS number 163442-67-9), 1,3-dicyclohexylcarbodiimide (DCC), $N$-hydroxysuccinimide, thionyl chloride $\left(\mathrm{SOCl}_{2}\right)$, propylamine, $N, N$-dimethylformamide (DMF), dimethyl sulfoxide (DMSO), and acetone were obtained commercially. [2.2]Paracyclophane-4-carboxylic acid 3 was prepared as described in the literature. ${ }^{14}$ All of the reactions were performed under a nitrogen or argon atmosphere.

\section{Synthesis of Cp-PAMAM-G3 4}

$\mathrm{N}$-Hydroxysuccinimide $(89 \mathrm{mg}, 0.78 \mathrm{mmol})$ and DCC $(0.17 \mathrm{~g}, 0.82 \mathrm{mmol})$ were added to [2.2]paracyclophane-4- 


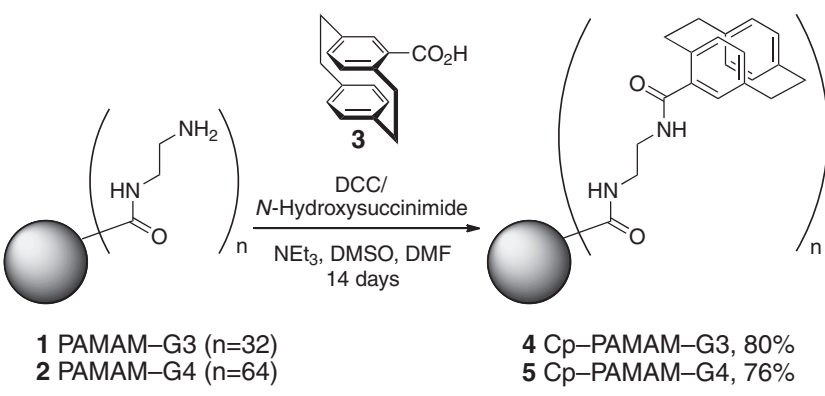

Scheme 1.

carboxylic acid $3(0.16 \mathrm{~g}, 0.65 \mathrm{mmol})$ dissolved in $\mathrm{DMF}$ $(4.0 \mathrm{~mL})$ at $0{ }^{\circ} \mathrm{C}$ and the resulting mixture was stirred for $4 \mathrm{~h}$. Then, PAMAM-G3 dendrimer $(88 \mathrm{mg}, 12.8 \mu \mathrm{mol})$ was dissolved in DMSO $(2.0 \mathrm{~mL}) . \mathrm{NEt}_{3}(0.13 \mathrm{~mL}, 0.95 \mathrm{mmol})$ was added to the solution, and the reaction mixture was stirred for $14 \mathrm{~d}$ at room temperature. The precipitated solid was filtered, and the filtrate was evaporated in vacuo. The residue was purified using Sephadex LH-20 column with DMF as an eluent. The dendrimer having [2.2]paracyclophane was further purified by reprecipitation from $\mathrm{DMF} / \mathrm{Et}_{2} \mathrm{O}(1.5 \mathrm{~mL} / 30 \mathrm{~mL})$. The precipitate was collected and dried in vacuo at $45^{\circ} \mathrm{C}$ for $72 \mathrm{~h}$ to give the target dendrimer $4(0.15 \mathrm{~g}, 10.2 \mu \mathrm{mol}, 80 \%)$ as a pale yellow solid. ${ }^{1} \mathrm{H} \mathrm{NMR}\left(\mathrm{CDCl}_{3}, 400 \mathrm{MHz}\right) \delta 2.33$ (br), 2.53 (br), 2.75 (br), 2.82-3.35 (br), 3.35-3.50 (br), 3.68 (br), 6.40-6.68 (br), 6.71 (br), 7.21 (br) ppm. IR (KBr) 3295, 3080, 2928, 2848, 1645, 1558, $719 \mathrm{~cm}^{-1}$.

\section{Synthesis of Cp-PAMAM-G4 5}

Cp-PAMAM-G4 5 was synthesized in the same manner as Cp-PAMAM-G3 4. Yield: $76 \%$. ${ }^{1} \mathrm{H}$ NMR $\left(\mathrm{CDCl}_{3}, 400 \mathrm{MHz}\right)$

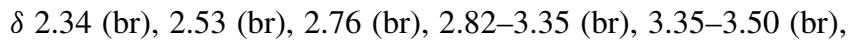
3.68 (br), 6.40-6.68 (br), 6.71 (br), 7.62 (br) ppm. IR (KBr) 3289, 3074, 2931, 2856, 1662, 1558, $720 \mathrm{~cm}^{-1}$.

Synthesis of $N$-propyl[2.2]paracyclophane-4-carboxamide 6

To [2.2] paracyclophane-4-carboxylic acid $3(0.13 \mathrm{~g}, 0.50$ $\mathrm{mmol}), \mathrm{SOCl}_{2}(8.2 \mathrm{~g}, 5.0 \mathrm{~mL}, 68.8 \mathrm{mmol})$ was added at room temperature, and the mixture was brought to $60^{\circ} \mathrm{C}$ and stirred for $4 \mathrm{~h}$. Excess amount of $\mathrm{SOCl}_{2}$ was removed under reduced pressure. The resulting [2.2]paracyclophane-4-carboxylic acid chloride was dissolved in $\mathrm{CH}_{2} \mathrm{Cl}_{2}(10 \mathrm{~mL})$ and cooled to $0{ }^{\circ} \mathrm{C}$. To this solution the mixture of propylamine $(60 \mathrm{mg}, 0.080 \mathrm{~mL}$, $1.0 \mathrm{mmol})$ and $\mathrm{NEt}_{3}(0.10 \mathrm{~g}, 0.14 \mathrm{~mL}, 1.0 \mathrm{mmol})$ was added dropwise over $5 \mathrm{~min}$. The solution was allowed to warm to room temperature and then stirred for $12 \mathrm{~h} . \mathrm{CH}_{2} \mathrm{Cl}_{2}(10 \mathrm{~mL})$ was added, and the reaction mixture was washed with $\mathrm{NaHCO}_{3}$ and brine. The organic layer was dried over $\mathrm{MgSO}_{4}$. After filtration of $\mathrm{MgSO}_{4}$, the solvent was evaporated and dried in vacuo. The residue was subjected to column chromatography on $\mathrm{SiO}_{2}$ with $\mathrm{CHCl}_{3}$ as an eluent to give compound $6(60 \mathrm{mg}$, $0.21 \mathrm{mmol}, 42 \%)$ as a white solid. ${ }^{1} \mathrm{H} \mathrm{NMR}\left(\mathrm{CDCl}_{3}, 400 \mathrm{MHz}\right)$ $\delta 0.98(\mathrm{t}, J=7.5 \mathrm{~Hz}, 3 \mathrm{H}), 1.61$ (sextet, $J=7.5 \mathrm{~Hz}, 2 \mathrm{H}), 2.83-$ $2.90(\mathrm{~m}, 1 \mathrm{H}), 2.90-3.18(\mathrm{~m}, 5 \mathrm{H}), 3.18-3.27(\mathrm{~m}, 1 \mathrm{H}), 3.36(\mathrm{t}$, $J=7.5 \mathrm{~Hz}, 2 \mathrm{H}), 3.65(\mathrm{~m}, 1 \mathrm{H}), 5.57$ (br, $1 \mathrm{H}), 6.40$ (d, $J=$
$8.0 \mathrm{~Hz}, 1 \mathrm{H}), 6.46(\mathrm{~d}, J=8.0 \mathrm{~Hz}, 1 \mathrm{H}), 6.53(\mathrm{~m}, 2 \mathrm{H}), 6.56(\mathrm{~d}$, $J=8.0 \mathrm{~Hz}, 1 \mathrm{H}), 6.63(\mathrm{~s}, 1 \mathrm{H}), 6.79(\mathrm{~d}, J=8.0 \mathrm{~Hz}, 1 \mathrm{H}) \mathrm{ppm}$. ${ }^{13} \mathrm{C} \mathrm{NMR}\left(\mathrm{CDCl}_{3}, 100 \mathrm{MHz}\right) \delta 11.48,23.03,34.77,35.11$, $35.27,35.41,41.50,131.52,131.94,132.43,132.55,134.87$, $134.97,135.23,135.89,139.00,139.12,139.83,140.17$, $169.22 \mathrm{ppm}$. IR (KBr) 3328, 2928, 2853, 1628, 1538, $718 \mathrm{~cm}^{-1}$. HRMS (FAB) calcd for $\mathrm{C}_{20} \mathrm{H}_{23} \mathrm{NO}, 294.1858$ $\left[\mathrm{M}+\mathrm{H}^{+}\right]$; found, 294.1856 .

\section{Synthesis of Ph-PAMAM-G4 7}

A solution of benzoyl chloride $(0.13 \mathrm{~g}, 0.11 \mathrm{~mL}, 0.91 \mathrm{mmol})$ in $\mathrm{DMF}(2.5 \mathrm{~mL})$, and $\mathrm{NEt}_{3}(0.13 \mathrm{~g}, 0.19 \mathrm{~mL}, 1.33 \mathrm{mmol})$ were added dropwise to PAMAM-G4 dendrimer $(67 \mathrm{mg}$, $4.73 \mu \mathrm{mol})$ dissolved in DMSO $(3.0 \mathrm{~mL})$ over $5 \mathrm{~min}$. Then, the resulting solution was stirred at room temperature for $5 \mathrm{~d}$. The precipitated solid was filtered off, and the filtrate was evaporated in vacuo. The residue was purified using Sephadex LH-20 column with methanol as the eluent. The resultant dendrimer having the benzene ring was further purified by reprecipitation from $\mathrm{DMF} / \mathrm{Et}_{2} \mathrm{O}(1.5 \mathrm{~mL} / 30 \mathrm{~mL})$. The precipitate was collected and dried in a vacuum at $45^{\circ} \mathrm{C}$ for $72 \mathrm{~h}$ to obtain target dendrimer 7 (74 mg, $3.55 \mu \mathrm{mol}, 75 \%)$ as a pale yellow solid. ${ }^{1} \mathrm{H} \mathrm{NMR}\left(\mathrm{CDCl}_{3}, 400 \mathrm{MHz}\right) \delta 2.43$ (br), 2.75 (br), 2.94 (br), 3.23-3.42 (br), 3.42-3.53 (br), 7.39 (br), 7.47 (br), 7.62 (br), 7.80 (br) ppm. IR (KBr) 3272, 3067, 2944, 2839, 1651, 1558, 1435, 708, $697 \mathrm{~cm}^{-1}$.

\section{RESULTS AND DISCUSSION}

Synthetic procedure of the target dendrimers is shown in Scheme 1. Ethylenediamine core amine-terminated PAMAMG3 and G4 dendrimers 1 and 2 with [2.2]paracyclophane-4carboxylic acid $\mathbf{3}$ were condensed to give the corresponding Cp-PAMAM-G3 and G4 dendrimers $\mathbf{4}$ and $\mathbf{5}$ in $80 \%$ and 76 yield, respectively, by using the DCC/N-hydroxysuccinimide system in $\mathrm{NEt}_{3} / \mathrm{DMF} / \mathrm{DMSO}$ at room temperature for $14 \mathrm{~d}$. Dendrimers 4 and $\mathbf{5}$ were soluble in polar solvents such as $\mathrm{MeOH}$, pyridine, DMF, DMSO, and partly soluble in $\mathrm{CH}_{2} \mathrm{Cl}_{2}$ and $\mathrm{CHCl}_{3}$. The structures of dendrimers were characterized by IR and ${ }^{1} \mathrm{H}$ NMR spectra. The number of [2.2]paracyclophane in dendrimers was estimated from the ${ }^{1} \mathrm{H}$ NMR integral ratio between aromatic protons and aminomethylene protons, suggesting that almost all chain ends of dendrimers $\mathbf{4}$ and $\mathbf{5}$ had [2.2]paracyclophane units. According to GPC analysis using DMF as an eluent, a unimodal peak with a relatively narrow molecular weight distribution $\left(M_{\mathrm{w}} / M_{\mathrm{n}}=1.30\right.$ for $\mathbf{4}$ and 1.37 for 5) ${ }^{15}$ was observed (Figure 1). It is considered that there are few defects in the structure. Their number-average molecular weights $\left(M_{\mathrm{n}}\right)$ were underestimated to be 8400 for $\mathbf{4}$ and 10400 for 5 using polystyrene standards (calculated $M_{\mathrm{n}}=14406.4$ for 4 and 29209.27 for 5) due to their compact structure. MALDITOF-MS analysis was carried out, and a typical broad spectrum of high-generation-PAMAM dendrimers was obtained by using a mixture of DHB and D- $(+)$-fucose $(\mathrm{v} / \mathrm{v}=1: 1)$ as a matrix. ${ }^{16}$ A parent peak was not observed for dendrimers $\mathbf{4}$ and $\mathbf{5}$ by MALDI-TOF-MS analysis, and thus we estimated the number 


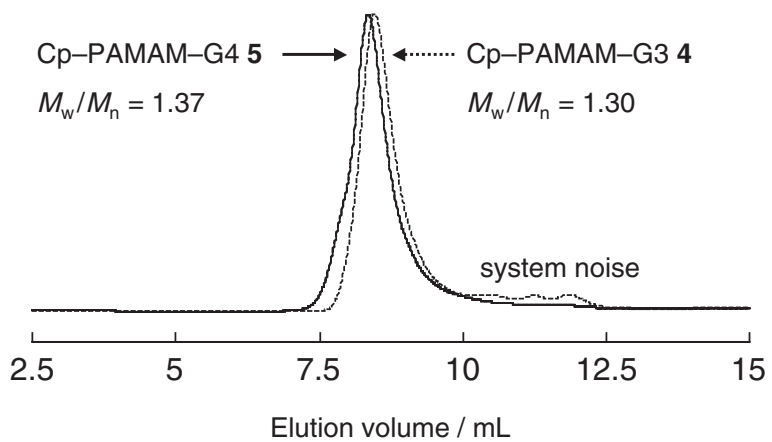

Figure 1. GPC charts of dendrimers 4 and 5 monitored by UV-8020 equipped with TSKgel $\alpha-3000$ column; eluent: DMF containing $\mathrm{LiBr}(10 \mathrm{mM})$, flow rate: $1.0 \mathrm{~mL} / \mathrm{min}$, detection: UV $254 \mathrm{~nm}$. Molecular weight distribution $\left(M_{\mathrm{w}} / M_{\mathrm{n}}\right)$ was estimated by polystyrene standards.

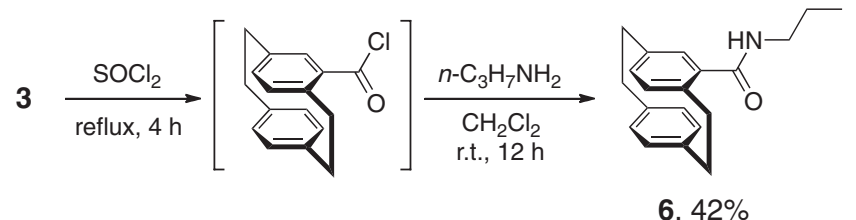

Scheme 2.

of the cyclophane unit in the dendrimers by the UV titration study (vide infra).

The optical properties of dendrimers $\mathbf{4}, \mathbf{5}$, and compound $\mathbf{6}$ (Scheme 2) were examined, and the results are summarized in Table I. In addition, normalized UV-vis spectra of compounds 4-6 are shown in Figure 2. All compounds 4-6 exhibited absorption at around $225 \mathrm{~nm}, 275 \mathrm{~nm}$, and $325 \mathrm{~nm}$, which are derived from the 4-carbamoyl[2.2]paracyclophane unit. Molar absorption coefficient $(\varepsilon)$ increased along with the number of the cyclophane unit (Table I). The wavelength of absorption shoulder and edge of dendrimers $\mathbf{4}$ and $\mathbf{5}$ were slightly redshifted in comparison with those of compound $\mathbf{6}$ (Figure 2), indicating that $\pi-\pi$ interaction among [2.2]paracyclophane units exists in the ground state. Figure 2 includes the absorption spectrum of G4 dendrimer 7 possessing phenyl groups in place of [2.2]paracyclophane. In the spectrum of 7, clear absorption at around 275 was not observed, and only the peak at around $225 \mathrm{~nm}(\log \varepsilon=4.80)$ derived from the $\pi-\pi^{*}$ transition of the phenyl group appeared (Figure 2).

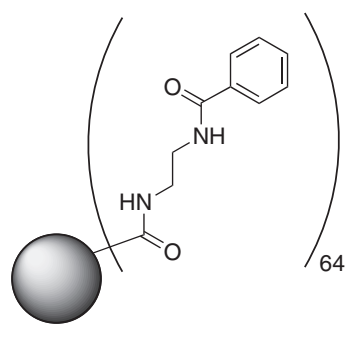

7 Ph-PAMAM-G4

An installation efficiency of [2.2]paracyclophane was estimated by the UV titration study by taking advantage of
Table I. Optical data of dendrimers 4 and $\mathbf{5}$, and model compound $\mathbf{6}$

\begin{tabular}{cccc}
\hline compound & $\mathrm{UV} \lambda / \mathrm{nm}^{\mathrm{a}}$ & $\log \varepsilon^{\mathrm{a}}$ & $\mathrm{PL} \lambda_{\max } / \mathrm{nm}^{\mathrm{a}, \mathrm{b}}$ \\
\hline $\mathbf{4}$ & $225,274,325$ & $4.89,4.26,3.20$ & 399 \\
$\mathbf{5}$ & $226,275,325$ & $5.26,4.75,3.76$ & 403 \\
$\mathbf{6}$ & $224,270,325$ & $3.40,2.64,2.41$ & 395 \\
\hline
\end{tabular}

a Absorption and emission spectra were recorded in dilute $\mathrm{CH}_{3} \mathrm{OH}$ solution at room temperature. ${ }^{\text {b}}$ Excited at $225 \mathrm{~nm}$.

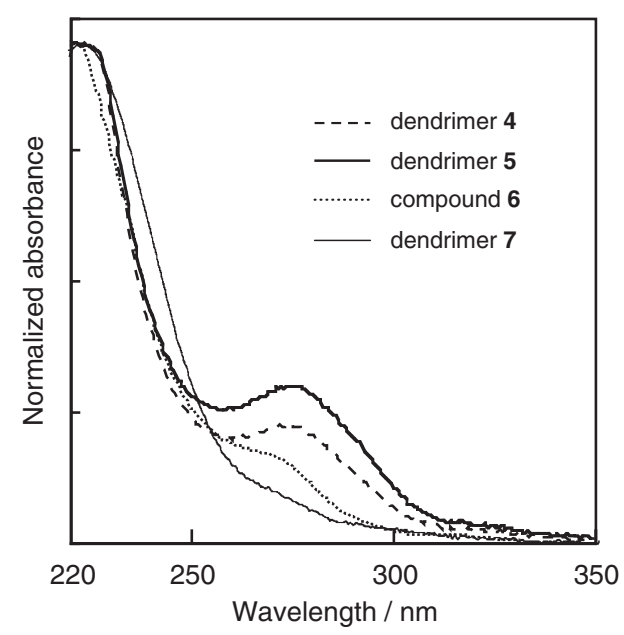

Figure 2. UV-vis absorption spectra of dendrimers $4,5,7$, and compound 6 in $\mathrm{CH}_{3} \mathrm{OH}$.

the formation of the charge-transfer (CT) complex between cyclophane units in the dendrimer and 7,7,8,8-tetracyanoquinodimethane (TCNQ). ${ }^{1 \mathrm{a}, 17}$ Figure 3 shows the CT formation scheme and the dependence of the UV spectrum on the TCNQ feed ratio against the [2.2] paracyclophane unit of dendrimer $\mathbf{5}$ in DMSO. By the addition of TCNQ, the absorbance due to CT complexation with TCNQ increased. The peak intensity ranging $600-1000 \mathrm{~nm}$ was saturated at $x=64$, and further increasing feed ratio of TCNQ did not affect the absorption of the anion radical of TCNQ (for example, $x=128$ ). This result indicates that approximately sixty-four [2.2]paracyclophanes are incorporated onto the dendrimer surface; namely, almost all terminal units of G4 dendrimer 5 are substituted with [2.2]paracyclophane units.

The association constant $\left(K_{\mathrm{CT}}\right)$ of the formation of the CT complex was determined by using the Benesi-Hildebrand equation. ${ }^{18}$ According to the Benesi-Hildebrand plots of [cyclophane unit]/absorbance $(\lambda=753 \mathrm{~nm})$ against $1 /[$ TCNQ] and [cyclophane unit]/absorbance $(\lambda=772 \mathrm{~nm})$ against $1 /[\mathrm{TCNQ}]$, the average of $K_{\mathrm{CT}}$ was found to be $14.7\left(\mathrm{~L} \mathrm{~mol}^{-1}\right)$. It is reported that $K_{\mathrm{CT}}$ of 4-vinyl[2.2]paracyclophane with tetracyanoethylene (TCNE) and 2,3-dichloro-5,6-dicyano-1,4benzoquinone (DDQ) are 15.74 and $36.84\left(\mathrm{~L} \mathrm{~mol}^{-1}\right)$, respectively. ${ }^{17 \mathrm{~d}}$ The smaller $K_{\mathrm{CT}}\left(14.7 \mathrm{~L} \mathrm{~mol}^{-1}\right)$ value in the present system is considered to be derived from the carbamoyl unit on [2.2]paracyclophane.

The fluorescence emission spectra of compounds 4-6 were obtained in a dilute $\mathrm{CH}_{3} \mathrm{OH}$ solution at room temperature, which were excited at $225 \mathrm{~nm}$ (Figure 4, right). All spectra 


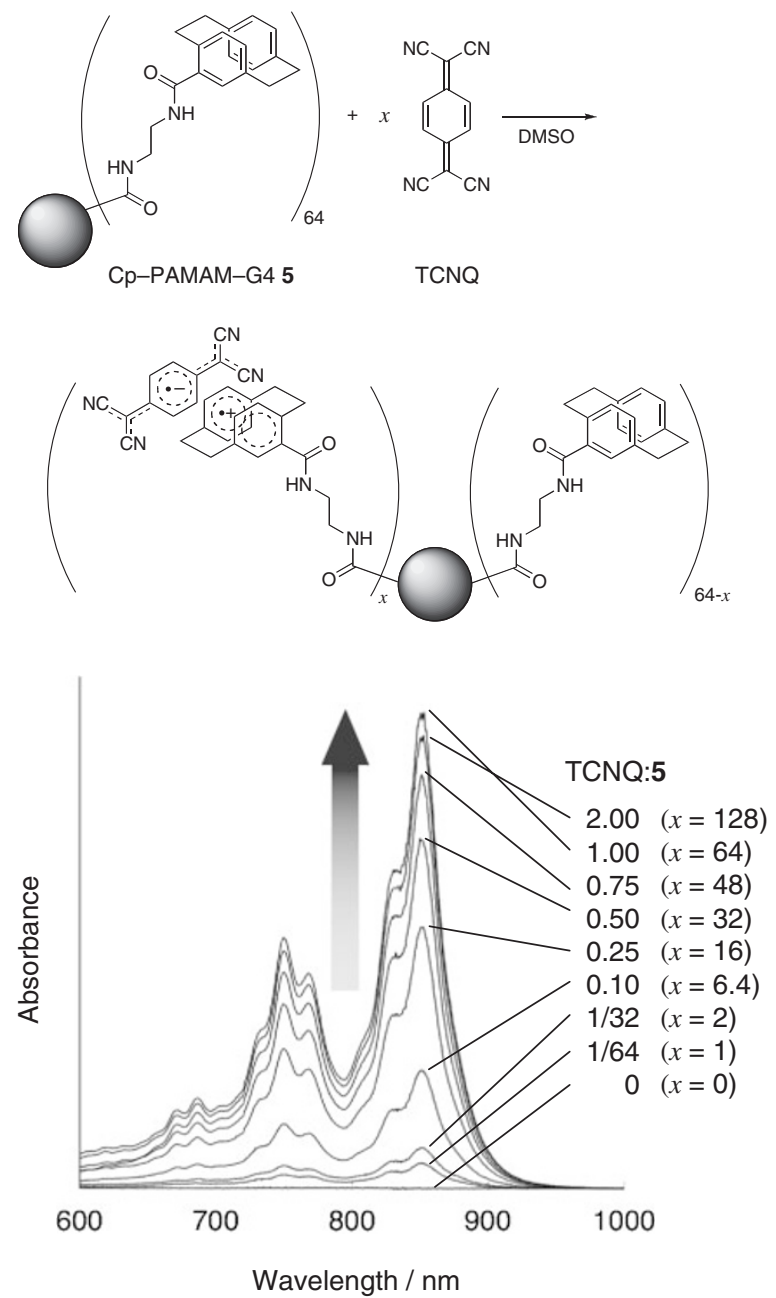

Figure 3. Scheme of the CT complex formation of dendrimer 5 with $\mathrm{TCNQ}$, and UV-vis absorption spectra of CT complexes of dendrimer 5 with TCNQ (absorption of the typical anion radical of TCNQ) in DMSO ([2.2]paracyclophane unit $\left.=2.2 \times 10^{-3} \mathrm{M}\right)$.

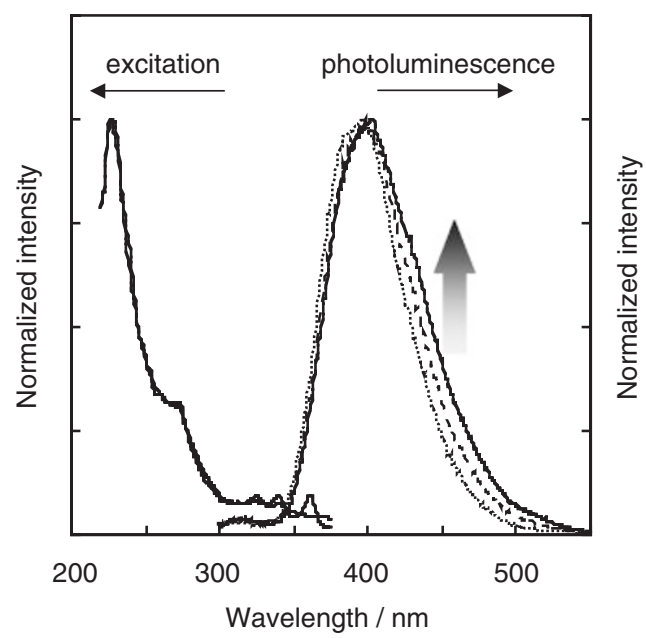

Figure 4. Fluorescence emission spectra of dendrimers $4(--)$ and $5(-)$ and compound $6(\ldots)$ in $\mathrm{CH}_{3} \mathrm{OH}$ excited at $225 \mathrm{~nm}$ (right). Excitation spectra of dendrimer 5 in $\mathrm{MeOH}$ monitored at 400 and $435 \mathrm{~nm}$.
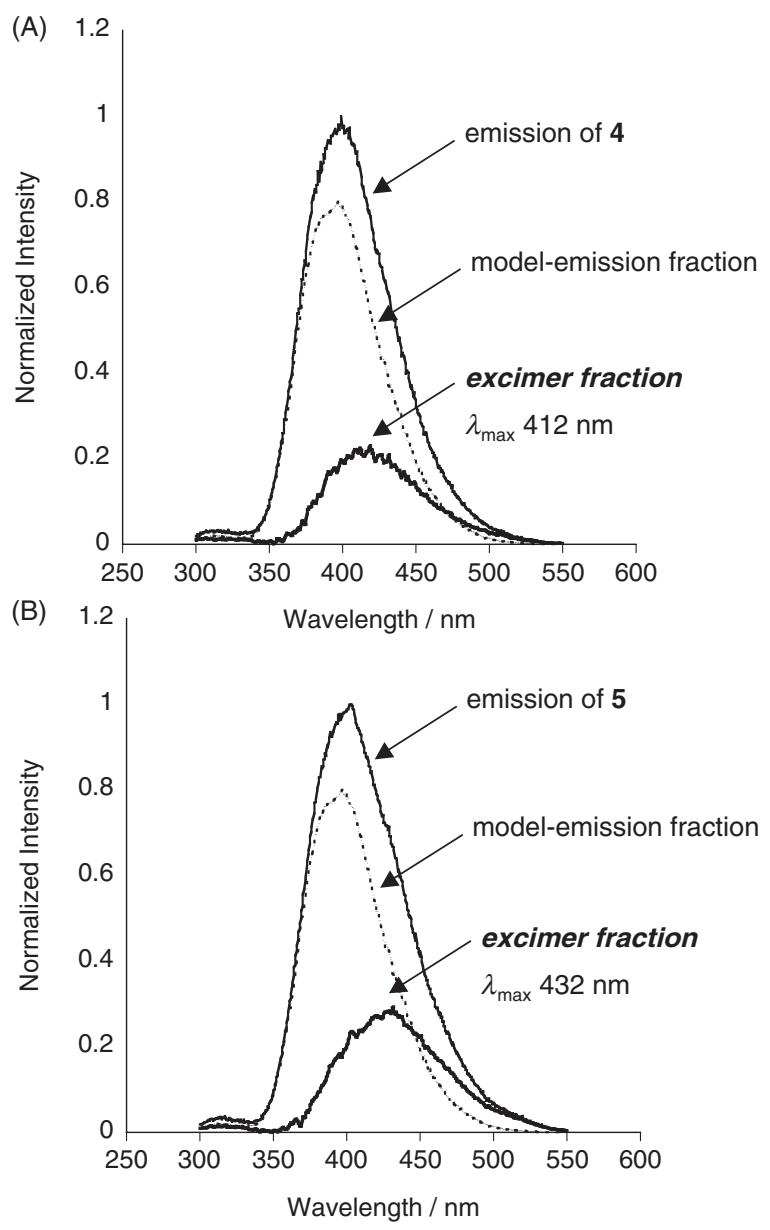

Figure 5. (A) Fluorescence emission spectra of dendrimer 4 (-), modelemission fraction (---), and excimer fraction $(-)$. (B) Fluorescence emission spectra of dendrimer $5(-)$, model-emission fraction (- - ), and excimer fraction (-).

were featureless with weak emission at around $400 \mathrm{~nm}$, which are assigned to emission from [2.2]paracyclophane (benzene excimer). Fluorescence quantum efficiencies of 4-6 were less than 0.1 , calculated by using anthracene in $\mathrm{EtOH}$ as a standard. As shown in Figure 4, emission ranging from 400 to $500 \mathrm{~nm}$ increased with the increase of the generation number of the dendrimers. Excitation spectra at $400 \mathrm{~nm}$ and $435 \mathrm{~nm}$ of dendrimer $\mathbf{5}$ were completely overlapped by normalization (Figure 4, left), indicating that emission at $400 \mathrm{~nm}$ and around $435 \mathrm{~nm}$ are derived from the same emitting species. Those results imply that the interaction of the neighboring [2.2]paracyclophane units on the dendrimer surface in the excited state led to the increase of emission around longer wavelength. This interpretation was supported by the spectra in Figure 5. Emission spectrum of the dendrimer is considered to be the total emission spectrum of the cyclophane units and its excimers; and thus, the emission spectrum was divided into the model-emission and excimer fractions, as shown in Figure $5 .{ }^{19}$ The excimer fraction of G4 dendrimer $\mathbf{5}$ exhibited the broad peak with peak maximum at $432 \mathrm{~nm}$, which possessed stronger emission with longer wavelength $\left(\lambda_{\max }\right.$ $412 \mathrm{~nm}$ ) than that of G3 dendrimer 4. 
In conclusion, we succeeded in the incorporation of [2.2]paracyclophane on the surface of the third- and fourthgeneration PAMAM dendrimers. These dendrimers are the first example of a [2.2]paracyclophane-containing dendrimer. The installation efficiency of the cyclophane units on the dendrimer surface is found to be high according to the NMR and UV titration studies. Investigation of their optical properties disclosed the intensity of emission from $\pi-\pi$ interaction among [2.2]paracyclophane units in the excited state accompanying the increase of the generation number of dendrimers.

Acknowledgment. This work was financially supported by Grant-in-Aid for Creative Scientific Research of "Invention of Conjugated Electronic Structures and Novel Functions," No. 16GS0209, from the Ministry of Education, Culture, Sports, Science, and Technology, Japan. Financial support from the Murata Science Foundation is also acknowledged.

Received: February 12, 2008 Accepted: May 9, 2008 Published: July 2, 2008

\section{REFERENCES}

1. a) F. Vögtle, "Cyclophane Chemistry: Synthesis, Structures and Reactions," John Wiley \& Sons, Chichester, 1993.

b) "Modern Cyclophane Chemistry," R. Gleiter and H. Hopf, Ed., Wiley-VCH, Weinheim, Germany, 2004.

2. C. J. Brown and A. C. Farthing, Nature, 164, 915 (1949).

3. a) W. J. Oldham, Jr., Y. J. Miao, R. J. Laghicotte, and G. C. Bazan, J. Am. Chem. Soc., 120, 419 (1998).

b) G. C. Bazan, W. J. Oldham, Jr., R. J. Laghicotte, S. Tretiak, V. Chernyak, and S. Mukamel, J. Am. Chem. Soc., 120, 9188 (1998).

c) S. Wang, G. C. Bazan, S. Tretiak, and S. Mukamel, J. Am. Chem. Soc., 122, 1289 (2000).

4. S. Mizogami and S. Yoshimura, J. Chem. Soc., Chem. Commun. 1985, 1736.

5. a) L. Guyard and P. Audebert, Electrochem. Commun., 3, 164 (2001). b) L. Guyard, P. Audebert, W. R. Dolbier, Jr., and J.-X. Duan, J. Electroanal. Chem., 537, 189 (2002).

c) F. Salhi, B. Lee, C. Metz, L. A. Bottomley, and D. M. Collard, Org. Lett., 4, 3195 (2002).

d) F. Salhi and D. M. Collard, Adv. Mater., 15, 81 (2003).

6. a) K. P. Sivaramakrishnan, C. Samyn, I. J. Westerman, D. T. Wong, and C. S. Marvel, J. Polym. Sci., Polym. Chem. Ed., 13, 1083 (1975). b) D. M. Chang and C. S. Marvel, J. Polym. Sci., Polym. Chem. Ed., 13, 2507 (1975).

c) S. Lin and C. S. Marvel, J. Polym. Sci., Polym. Chem. Ed., 21, 1151 (1983).

7. a) J. Furukawa and J. Nishimura, Polym. Lett. Ed., 14, 85 (1976). b) D. T. Glatzhofer and D. T. Longone, J. Polym. Sci., Part A: Polym. Chem., 24, 947 (1986).

c) D. T. Longone and D. T. Glatzhofer, J. Polym. Sci., Part A: Polym. Chem., 24, 1725 (1986).

d) J. Ulański, J. Kubacki, I. Glowacki, M. Kryszewski, and D. T. Glatzhofer, J. Appl. Polym. Sci., 44, 2103 (1992).

e) D. J. Guerrero and D. T. Glatzhofer, J. Polym. Sci., Part A: Polym. Chem., 32, 457 (1994).

f) S. Iwatsuki, T. Itoh, M. Kubo, and H. Okuno, Polym. Bull., 32, 27 (1994).

8. a) W. Wang, J. Xu, and Y.-H. Lai, Org. Lett., 5, 2765 (2003).

b) W. Wang, J. Xu, Y.-H. Lai, and F. Wang, Macromolecules, 37, 3546 (2004). c) W. Wang, J. Xu, Z. Sun, X. Zhang, Y. Lu, and Y.-H. Lai, Macromolecules, 39, 7277 (2006).

d) W. Wang, J. Xu, and Y.-H. Lai, J. Polym. Sci., Part A: Polym. Chem., 44, 4154 (2006).

9. a) Y. Morisaki and Y. Chujo, Angew. Chem., Int. Ed., 45, 6430 (2006).

b) Y. Morisaki and Y. Chujo, Prog. Polym. Sci., 33, 346 (2008).

10. a) Y. Morisaki and Y. Chujo, Macromolecules, 35, 587 (2002).

b) Y. Morisaki and Y. Chujo, Chem. Lett. 194 (2002).

c) Y. Morisaki, T. Ishida, and Y. Chujo, Macromolecules, 35, 7872 (2002).

d) Y. Morisaki and Y. Chujo, Polym. Bull., 49, 209 (2002).

e) Y. Morisaki and Y. Chujo, Macromolecules, 36, 9319 (2003).

f) Y. Morisaki, T. Ishida, and Y. Chujo, Polym. J., 35, 501 (2003).

g) Y. Morisaki and Y. Chujo, Macromolecules, 37, 4099 (2004).

h) Y. Morisaki, T. Ishida, H. Tanaka, and Y. Chujo, J. Polym. Sci. Part A: Polym. Chem., 42, 5891 (2004).

i) Y. Morisaki, N. Wada, and Y. Chujo, Polym. Bull., 53, 73 (2005).

j) Y. Morisaki and Y. Chujo, Bull. Chem. Soc. Jpn., 78, 288 (2005).

k) Y. Morisaki, N. Wada, and Y. Chujo, Polymer, 46, 5884 (2005).

1) Y. Morisaki and Y. Chujo, Tetrahedron Lett., 46, 2533 (2005).

m) Y. Morisaki, T. Ishida, and Y. Chujo, Org. Lett., 8, 1029 (2006).

11. a) D. A. Tomalia, H. Baker, J. Dwald, M. Hall, G. Kallos, S. Martin,

J. Roeck, J. Ryder, and P. Smith, Polym. J., 17, 117 (1985).

b) G. R. Newkome, Z. Yao, G. R. Baker, and V. K. Gupta, J. Org. Chem., 50, 2004 (1985).

c) C. J. Hawker and J. M. J. Fréchet, J. Am. Chem. Soc., 112, 7638 (1990).

12. a) D. A. Tomalia, A. M. Naylor, and W. A. Goddard, III, Angew. Chem., Int. Ed., 29, 138 (1990).

b) G. R. Newkome, C. N. Moorefield, and F. Vögtle, "Dendritic Molecules: Concepts, Syntheses, Perspectives,” VCH, Weinheim, 1996.

c) G. R. Newkome, C. N. Moorefield, and F. Vögtle, "Dendrimers and Dendrons, Concepts, Syntheses, Applications," Wiley-VCH, Weinheim, 2001.

d) "Dendrimers and Other Dendritic Polymers," J. M. J. Fréchet and D. A. Tomalia, Ed., Wiley, Chichester, 2001.

13. a) T. M. Billeci and J. T. Stults, Anal. Chem., 65, 1709 (1993). b) A. I. Gusev, W. R. Wilkinson, A. Proctor, and D. M. Hercules, Anal. Chem., 67, 1034 (1995).

c) J. Peterson, V. Allikmaa, J. Subbi, T. Pehk, and M. Lopp, Eur. Polym. J., 39, 33 (2003).

14. V. Rozenberg, N. Dubrovina, E. Sergeeva, D. Antonov, and Y. Belokon, Tetrahedron: Asymmetry, 9, 653 (1998).

15. Molecular weight distribution $\left(M_{\mathrm{w}} / M_{\mathrm{n}}\right)$ was 2.6 for both commercially available PAMAM dendrimers $\mathbf{1}$ and $\mathbf{2}$ under the same condition.

16. Generally, in the MALDI-TOF-MS analysis, lower-generationPAMAM dendrimers and higher-generation-PAMAM dendrimers show a complicated fragmentation and considerably broad peaks, respectively; therefore, it is quite difficult to detect a parent peak of higher-generation-PAMAM dendrimers. For example: J. Subbi, R. Aguraiuja, R. Tanner, V. Allikmaa, and M. Lopp, Eur. Polym. J., 41, 2552 (2005), and reference $13 \mathrm{c}$.

17. It is known that cyclophanes can form CT complexes with electron acceptors such as TCNQ, 2,3-dichloro-5,6-dicyano-1,4-benzoquinone (DDQ), tetracyanoethylene (TCNE), and so on. For example: a) L. A. Singer and D. J. Cram, J. Am. Chem. Soc., 85, 1080 (1963).

b) A. E. Mourad, E. H. Eltamany, and H. Hopf, Z. Phys. Chem. (Leipzig), 267, 187 (1986).

c) A. E. Mourad, A. E.-D. A. Hassan, and J. Dannheim, Bull. Chem. Soc. Jpn., 62, 1379 (1989).

d) A. A. Aly, Spectrochim. Acta., 55A, 79 (1999).

18. H. A. Benesi and J. H. Hildebrand, J. Am. Chem. Soc., 71, 2703 (1949).

19. H. Benten, J. Guo, H. Okita, S. Ito, M. Yamamoto, N. Sakumoto, K. Hori, Y. Tohda, and K. Tani, J. Phys. Chem. B, 111, 10905 (2007). 